\title{
Developing Strategies for Improving Government Data Openness in China: A Quantitative Analysis and Assessment
}

\author{
Zhang Xiaojuan ${ }^{1,2}$, Sun Cheng ${ }^{1}$, Xiang Jinpeng ${ }^{1,2}$ \\ ${ }^{1}$ School of Information Management, Wuhan University, Wuhan, China \\ ${ }^{2}$ Center for Studies of Information Resources, Wuhan University, Wuhan, China
}

Email address:

xjz@whu.edu.cn (Zhang Xiaojuan),2651590009@qq.com (Sun Cheng)

\section{To cite this article:}

Zhang Xiaojuan, Sun Cheng, Xiang Jinpeng. Developing Strategies for Improving Government Data Openness in China: A Quantitative Analysis and Assessment. International Journal of Information and Communication Sciences. Vol. 3, No. 3, 2018, pp. $75-87$. doi: $10.11648 /$ j.ijics.20180303.11

Received: August 19, 2018; Accepted: September 11, 2018; Published: October 19, 2018

\begin{abstract}
This paper aims to develop successful strategies for improving government data openness at state level in China based on its current status of Open Government Data (OGD) against the Open Data Barometer (ODB). For this purpose, firstly, primary and secondary data on the index scores of countries around the world from 2013 to 2016 were collected through the websites of ODB, followed by a statistical analysis of the data which showed the correlation of the indicators of the ODB, emphasized by the co efficiency between the indicators. Secondly, through the quantitative analysis of their survey on individual indicators in China, the authors found that the overall readiness of China's OGD is acceptable, especially at the local government level, but its implementation and impact is still relatively backward. Further analysis of the assessment results of sub indicators identified the specific problems in China's OGD. Finally, based on the correlation of indicators and the results of China's assessment, the authors proposed the strategies for the improvement of China's OGD from the perspectives of readiness and implementation, which will facilitate an overall upgrade of national government data openness in the way of improving the performance on individual backward sub-indicators and addressing the identified problems. The "vertical" improvement of China's readiness is featured with a promotion of the common upgrade of execution and impact while the "horizontal" increase of execution leads to the development of subsequent impact. In addition, a comparative study showed that the former strategy has a slight advantage over the latter in terms of the expected results. This research is of practical significance as it will help to identify, prioritize, and address the most critical issues of government data openness in China.
\end{abstract}

Keywords: Open Government Data, Open Data, Open Data Barometer, Strategies, Assessment, China

\section{Introduction}

In January 2009, the Obama Administration of USA signed Memorandum on Transparency and Open Government, and launched the open government data (OGD) platform Data. gov in May of the same year; [1] In June 2009, the British Government also officially began the "freeing up public data" Initiative and launched Data. Gov. UK in January 2010. [2] Since then, the OGD movement has developed rapidly around the world and penetrated into every corner of the globe. Local governments in China have actively promoted data openness and the cities like Beijing and Shanghai have taken the lead to start the OGD work. [3] According to
Report of China's Local Open Government Data Platform issued by Digital and Mobile Governance Lab of Fudan University in 2018, China has established 46 local OGD platforms as of April 2018. [4] The successive establishment of OGD platforms has promoted the development of government data openness in China.

With continuous advancement of OGD movement, the assessment of government data openness has also been conducted in recent years. And the assessment results gradually show the achievement and problems of government data openness in China and its status in the international community. In consideration of this, how to promote the level of government data openness and what the strategies 
are to improve it have also become a topic of great practical significance.

Currently, the literature on promoting government data openness in China can be roughly divided into two categories. The first is based on OGD assessment. Some studies start from the assessment results of open data barometer (ODB) and believe that China should make efforts mainly in policy formulation, policy implementation, policy assessment and policy feedback. [5] The second is the strategies put forward on the basis of foreign advanced experiences and investigation and research on current state of China's OGD. The second one has an absolute advantage in quantity. Its recommendations focus on policy formulation and implementation, institutional mechanisms and inter-department coordination, establishment of unified open data portal, assurance of open data quality and quantity, strengthening the applications of serving the society with open data and enhancing involvement of the social public. [6-11] Some scholars also refer to foreign advanced practices and point out that efforts should be made to formulate the standard valuing the quality of open data, value the re-use of open data, focus on people's livelihood service and enhance the public-private partnership to promote the government data openness. [12-15] Both the first and second categories of literature basically adopt the qualitative research method and the development strategy of OGD proposed from different perspectives shows the characteristics of convergence.

As one of the representative international assessment projects, the ODB assessment results reflect the current state of government data openness in China to a certain extent. Based on the assessment results data provided by ODB website, [16] this paper analyzes the problems of government data openness in China, explores the strategies for improving government data openness in China from the perspective of assessment indexes and quantitatively analyzes the expected results after promotion, with an aim to provide concrete and feasible suggestions for promoting government data openness in China.

\section{ODB and Its Index Correlation Analysis}

The current international assessment projects with assessment scope covering every country in the world are the open data readiness assessment of the World Bank, Global Open Data Index, ODB, open government data survey of the United Nations and so on. Among them, the ODB has the most comprehensive assessment contents, including three aspects: readiness, implementation and impact. The open data readiness assessment of the World Bank only targets at the readiness, the Global Open Data Index only targets at implementation and the open government data survey of the United Nations is part of the investigation for E-government development of the United Nations and does not provide detailed assessment results. Therefore, this paper selects the ODB for specific research.

\subsection{Introduction to $O D B$}

The ODB was jointly developed by The World Wide Web Foundation and Open Data Institute. The first Open Data Barometer Global Report was issued in 2013 and altogether four reports have been issued as of 2016. As one of international OGD assessment systems, ODB analyses global trends, and provides comparative data on countries and regions with an aim to uncover the true prevalence and impact of open data initiatives around the world. [17]

The assessment indexes of ODB include readiness, implementation and impact. The readiness index assesses the preparation at earlier stage and its sub-indexes include government policies, government action, entrepreneurs and business, citizens and civil society; the implementation index assesses the dataset made public by the government and the dataset includes innovation dataset, social policy dataset and accountability dataset; the impact index assesses the impacts at the later stage, including the political, economic and social impacts. The assessment of the ODB is conducted by scoring specific assessment questions, where sub-indexes of readiness and impact are directly composed of assessment questions. The assessment questions are at the lowest tier in the index system. The implementation consists of index datasets and the assessment questions are fixed, that is, these assessment questions are examined for each dataset.

The three indexes cover every stage of government data openness from preparation at the earlier stage to the implementation in the middle stage and to the impacts at the later period. The corresponding sub-indexes reflect the details of every aspect of government data openness. Hence, ODB becomes one of the most influential international assessment systems.

\subsection{Index Correlation of $\mathrm{ODB}$}

Since the three indexes of ODB have stage characteristics, they are correlated. The full and effective readiness can guarantee the implementation; the open use of dataset in implementation can promote rapid expression of impact; and the promotion of impact at the later stage can also further drive the promotion of readiness and implementation. The three promote and influence each other. [18] In the assessment results of ODB, the relevance of index scores of various countries in the world also confirms the index correlation.

\subsubsection{High Correlation Between Readiness and Implementation}

After comprehensive analysis of the results of the four assessments, the authors found that, among the index assessment results of ODB, the average level of readiness is better than that of implementation and better than that of impact and the impact level is generally low at present. Therefore, there existing most obvious correlation between readiness and implementation. Figure 1 is a scatter diagram of results of readiness and implementation assessment in 2016. 


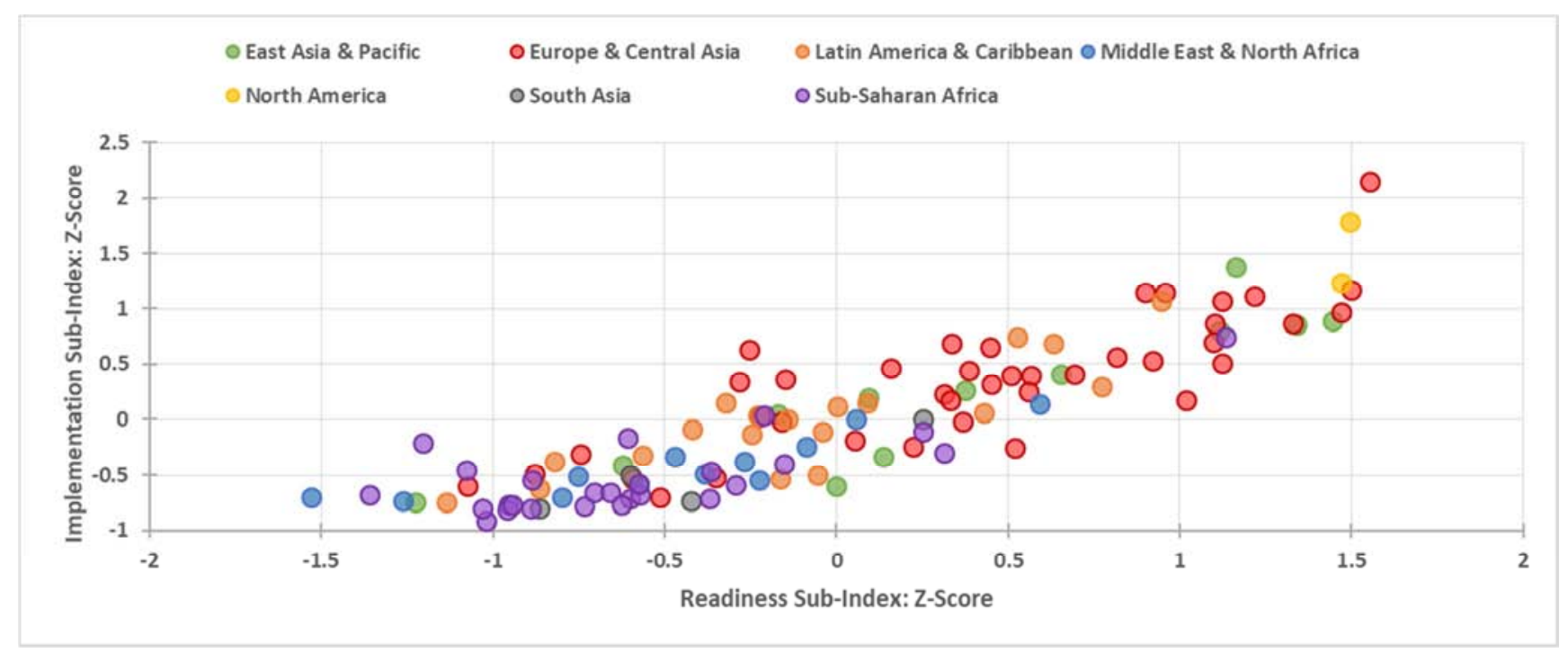

Figure 1. Scatter diagram of readiness and implementation assessment results of ODB in 2016.

In this paper, the Z-score conversion on score of each sub-index is performed with the data processing method of ODB and thus standardized data of the three indexes is obtained. The Figure 1 shows that there was a significant positive correlation between the readiness and implementation in the countries around the world in 2016 and the correlation coefficient was 0.86 , indicating a strong correlation. It can be observed from the assessment results that the correlation coefficient between readiness and implementation from 2013 to 2016 has been the highest and the correlation coefficient reached 0.92 in 2015. This can indicate that there is strong correlation between readiness and implementation. In Figure 1, the various regions of the world are distinguished by color. The countries with higher overall level in Europe, Central Asia and North America have an earlier start and have made certain achievements in readiness and implementation. Therefore, the index correlation is more obvious.

\subsubsection{Correlation Between Readiness and Impact}

Although the impact of global government data openness is generally low at present, correlation still exists among the indexes and both readiness and implementation are correlated to impact. According to the 2014 Open Data Barometer Global Report, the impact of open data not only comes from the opening-up of dataset, but also more relies on the overall national practices constituting the OGD initiative. In other words, there is a stronger correlation between impact and readiness than that between impact and implementation. The results of latest assessment of readiness and impact in 2016 are shown in Figure 2.

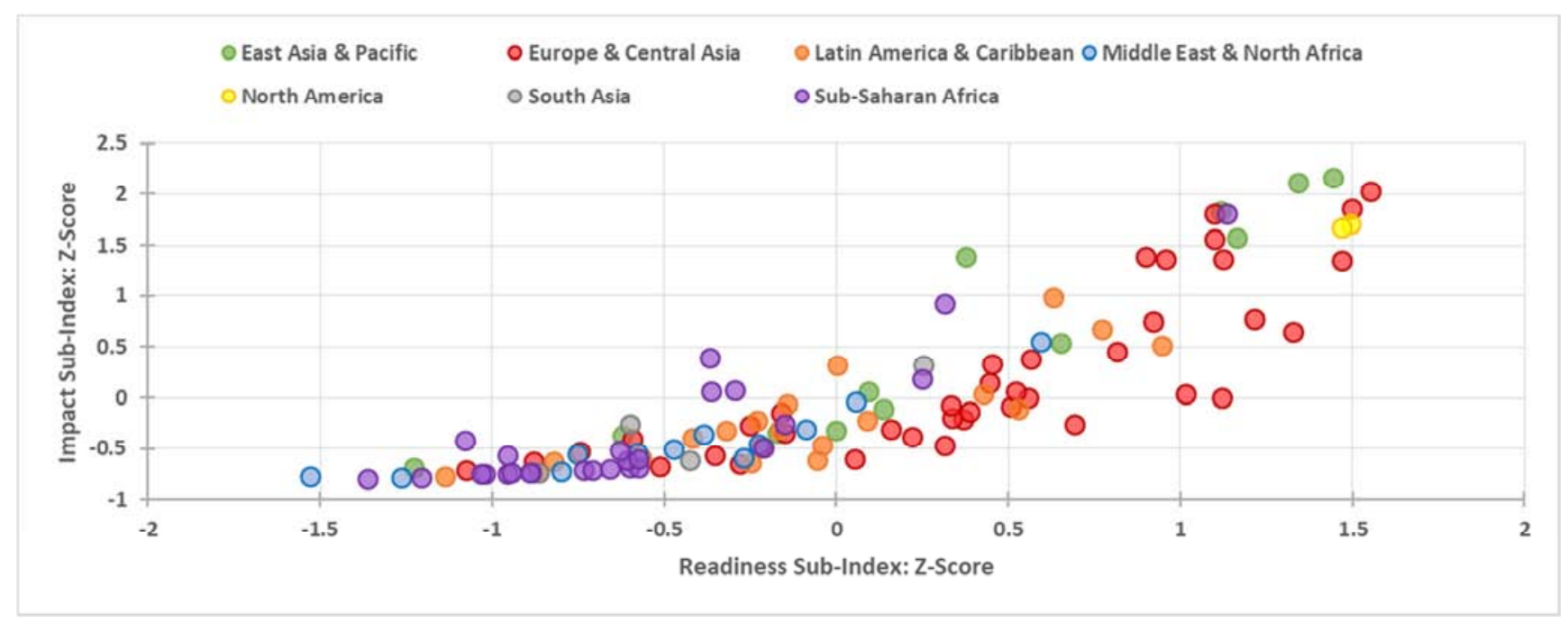

Figure 2. Scatter diagram of readiness and impact assessment results of ODB in 2016.

In the assessment results of ODB in 2016, the correlation coefficient between readiness and impact in countries around the world was 0.83 , a strong correlation. The impact gap of different countries becomes even more significant here. The leading regions and countries have stronger index correlation. For instance, a correlation between readiness and impact is 
demonstrated in most countries in Europe and Central Asia while it is difficult to reflect the correlation between readiness and impact in the backward areas like Sub-Saharan African countries since the impact has not yet shown.

\subsubsection{Correlation Between Implementation and Impact}

There is also a correlation between implementation and impact of ODB and the assessment results are shown in Figure 3.

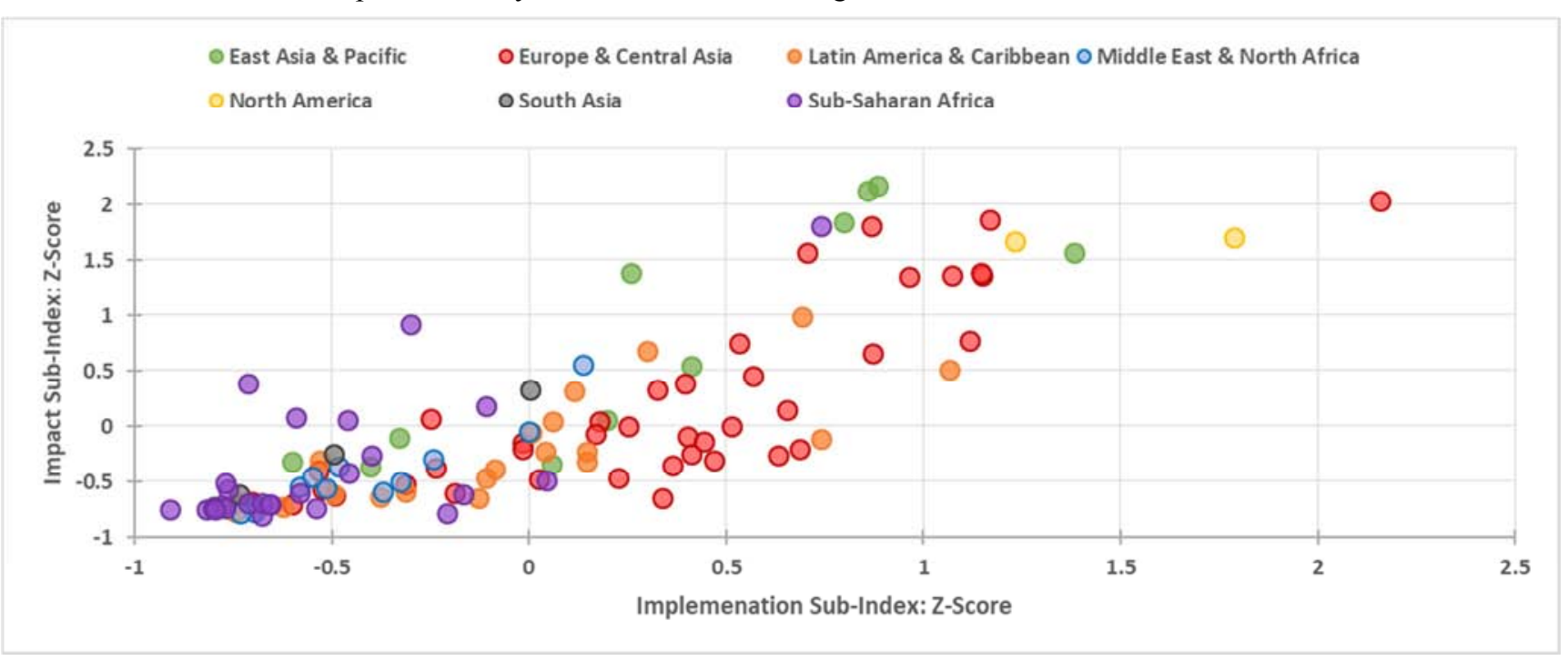

Figure 3. Scatter diagram of implementation and impact assessment results of ODB in 2016.

The correlation coefficient between the implementation and impact in countries around the world in 2016 was 0.79 , which is weaker than the correlation between readiness and impact. This is consistent with the conclusion in the 2014 Open Data Barometer Global Report which states that the correlation between implementation and impact is weaker than that between readiness and impact. Not only the implementation is highly correlated with readiness, but also the impact is more dependent on readiness. So readiness is the basis for government data openness and strengthening readiness is conducive to the overall progress of government data openness in a country.

\section{The Strategies for Improving Government Data Openness in China}

\subsection{The Current State of Government Data Openness in China}

Since 2013, more and more countries have been included in ODB. In the four rounds of assessment so far, China's rankings in terms of government data openness are shown in Table 1.

Table 1. Statistics on China's rankings in ODB assessments from 2013 to 2016.

\begin{tabular}{llll}
\hline Assessment time & Countries assessed & China's ranking & Change in China's ranking \\
\hline 2013 & 77 & 61 & $\uparrow 15$ \\
2014 & 86 & 46 & $\downarrow$ \\
2015 & 92 & 55 & $\downarrow$ \\
2016 & 115 & 71 & $\downarrow 16$ \\
\hline
\end{tabular}

Although ODB is only a tool for assessing the government data openness and cannot fully and accurately reflect the level of government data openness in China, it is still of reference significance in general. It can be found from the table that China ranked at relatively lower positions in the ODB assessments. China has once reached the global average level only in light of readiness and its implementation and impact have been below the global average level. Based on the assessment results of ODB in 2016, this paper analyzes the items that China has relatively higher and lower scores and summarizes the existing achievements and specific problems of government data openness in China by referring to the data of the previous three assessments.

\subsubsection{The Current State of Readiness of Government Data Openness in China}

The readiness index in ODB of 2013 to 2014 included three sub-indexes: government, citizens and civil society, entrepreneurs and business. From 2015, the government sub-index was detailed into the government policies sub-index and government action sub-index. The scores of the sub-indexes of readiness are obtained by examining the 14 assessment questions. Then Z-score conversion on scores of all assessment questions is performed and the average value is obtained to get the overall score of readiness.

When comparing with the average value of Asia-Pacific Region, only the score of government action in 2016 was 
higher while the other three sub-indexes were lower. Of which, the score of government policies was much lower. This indicates that, in China, the government action precedes government policies. When the central government has not officially issued the policies and regulations concerning government data openness, some local governments have already begun to open up government data.

The ranking interval of China (represented by the blue blocks) in terms of the score of 14 readiness assessment questions among the 115 assessed countries is shown in Figure 4. It can be observed from the figure that China has three items with higher score and ranking among top $20 \%$. They are CSOC, CITY and GITR. China also has three items with lower score and ranking among bottom $20 \%$. They are POLI, DPL and FH.

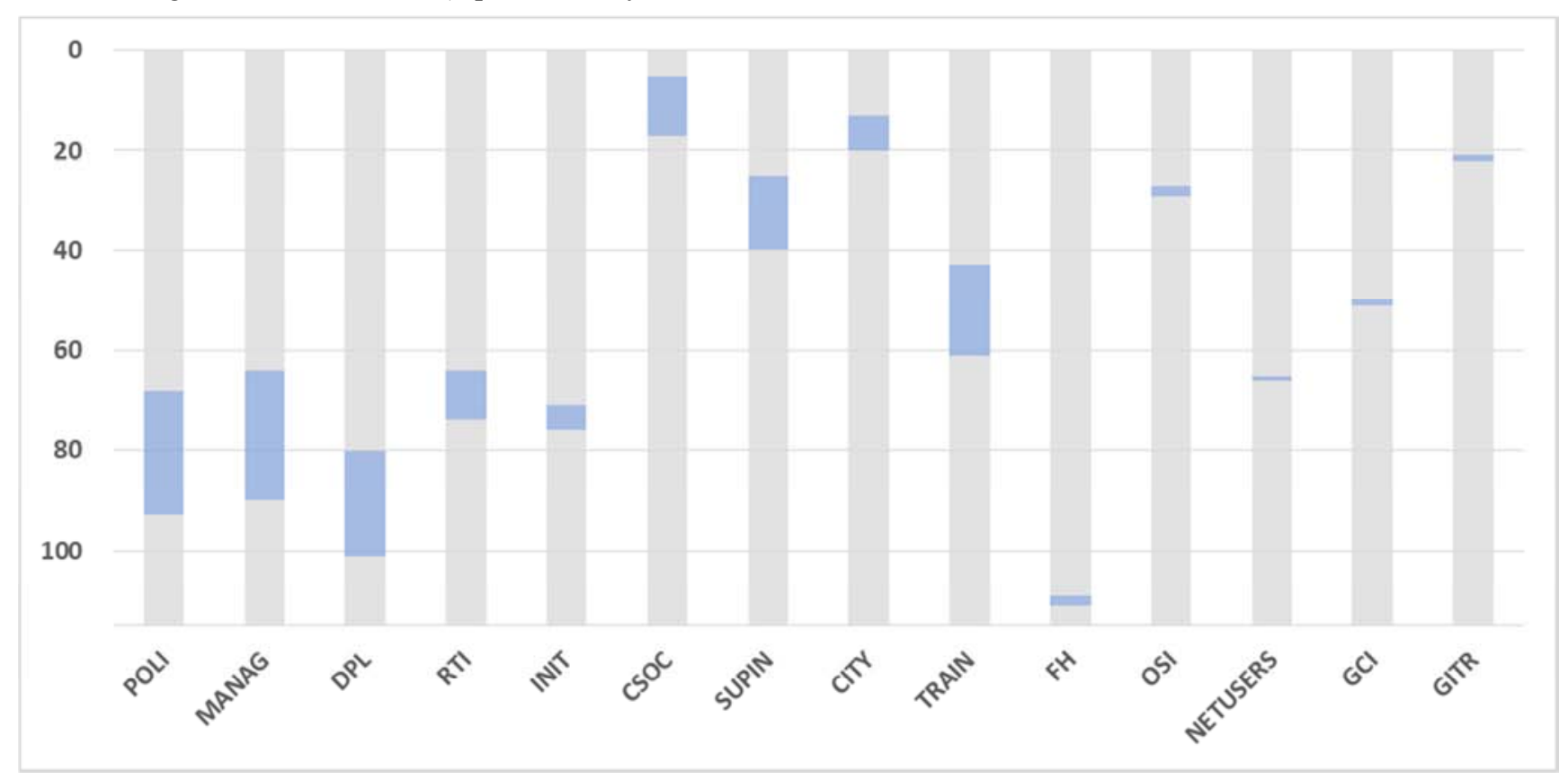

Figure 4. Ranking intervals of China in terms of score of readiness assessment questions in 2016.

Among the assessment questions that China has higher score, the CSOC means "to what extent are civil society and information technology professionals engaging with the government regarding open data?" The total score is 10 points, and China scored 8 points, ranking between $4 \%$ and $15 \%$. The CITY means "to what extent are city, regional and local governments running their own open data initiatives?" The total score is 10 points, and China scored 7 points, ranking between $11 \%$ and $17 \%$. The GITR refers to "importance of ICT to government vision". The total score is 10 points and China scored 4.69 points, ranking between $18 \%$ and $19 \%$. This indicates that China's social public or information technology professionals relatively more actively participate in government data openness, that there is certain development in local government data openness and that the government attaches great importance to information and communication technology. Among the assessment questions that China has lower score, the POLI means "to what extent is there a well-defined open data policy and/or strategy in the country?" The total score is 10 points and China scored one point. This indicates that China has not yet put forward clear open data policy or strategy at the national level. The DPL means "to what extent is there a robust legal or regulatory framework for protection of personal data in the country?" The total score is 10 points and China scored 2 points, indicating that China does not pay much attention to the personal data protection in the government data opening-up process. Finally, the FH refers to "freedom house political freedoms and civil liberties". The total score is 100 points and China scored 16 points. This is the assessment question that China has the poorest performance.

\subsubsection{The Current State of Implementation of Government Data Openness in China}

In 2013, the ODB assessed the openness of 14 datasets. Since 2014, public contracting dataset has been added, and a total of 15 datasets are being assessed at present.

From the perspective of assessment index, the 15 datasets are generalized into three categories: innovation dataset, social policy dataset and accountability dataset. In the implementation assessment, China has no sub-indexes with scores exceeding the average value of the Asia-Pacific region. In particular, the score of innovation dataset was far much lower. In light of the specific assessed dataset, as shown in Figure 5, China's ranking in terms of dataset is not ideal. Only the national statistics dataset and public transport timetable dataset rank among top $60 \%$. China had relatively lower rankings in terms of other datasets and the national election data is the dataset with lowest openness level. This shows that China's government data has not been sufficiently and truly opened up to satisfy the definition of Open Knowledge Foundation on "open data". 


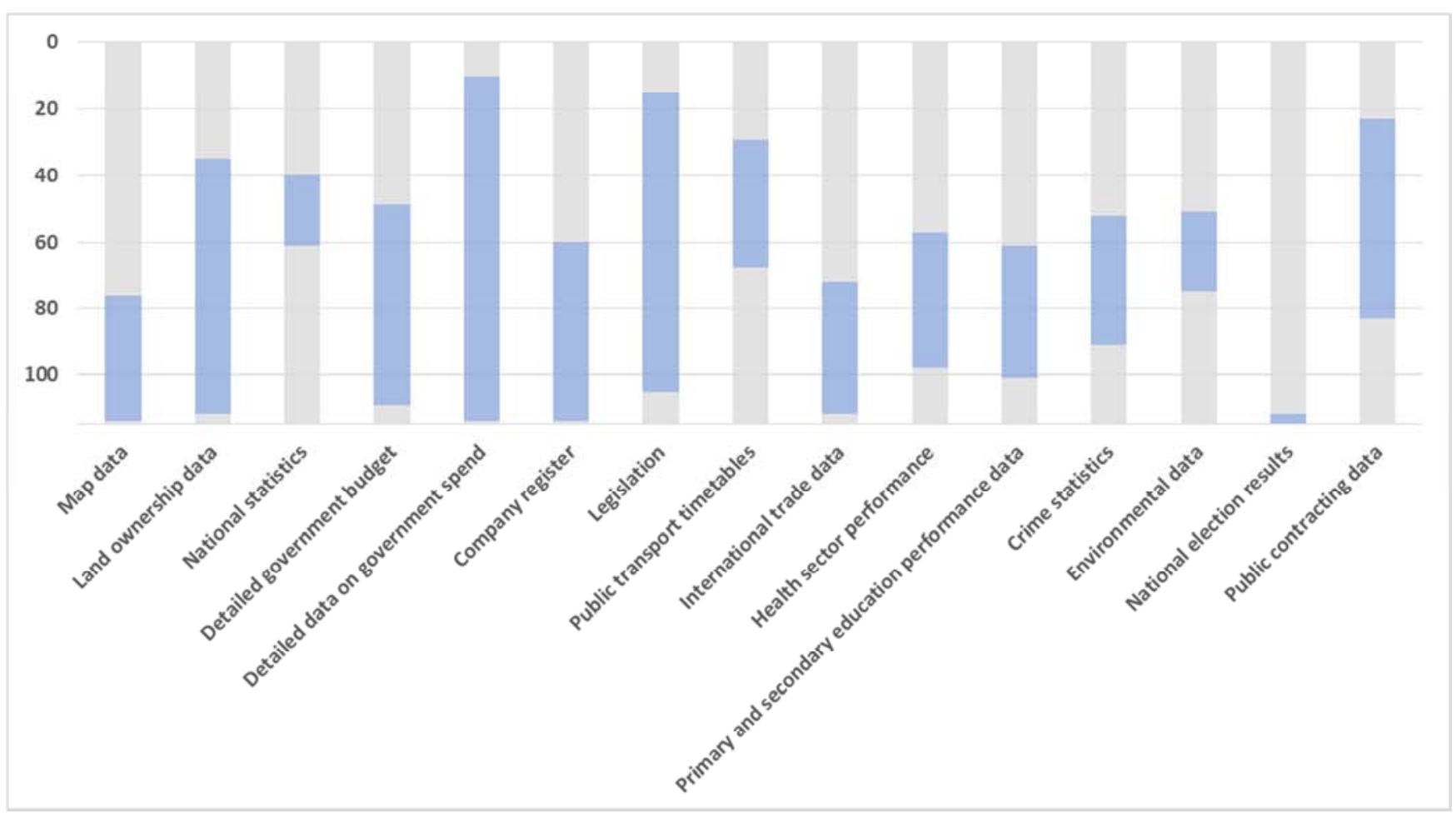

Figure 5. Ranking intervals of China in terms of datasets in implementation assessment in 2016.

Most of open datasets in China only satisfy the two assessment questions: Does the data exist and is it available online from government in any form? And all datasets do not satisfy the following three assessment questions: (1) Is the machine-readable and reusable data available as a whole? (2) Is the data openly licensed? and (3) Are data identifiers provided for key elements in the dataset? As shown in Figure 6 , except for the national statistics dataset, all other datasets are not highly opened up. Although the public transport timetable ranks among top $60 \%$, fewer assessment questions of this dataset were satisfied and the score is still much lower than that of the countries with higher scores. Therefore, the openness of China's dataset should not be understood only from the ranking of dataset, but should from the perspective of whether the assessment question is satisfied or not. As shown in Figure 6, except for the national statistics dataset, most of datasets of China are far from sufficiently opened up and measures should be found from the assessment questions.

\begin{tabular}{|c|c|c|c|c|c|c|c|c|c|c|c|c|c|c|c|}
\hline & $\begin{array}{l}\text { Map } \\
\text { Data }\end{array}$ & $\begin{array}{l}\text { Land } \\
\text { Owner } \\
\text { ship } \\
\text { Data }\end{array}$ & $\begin{array}{l}\text { Natio } \\
\text { nal } \\
\text { Stati } \\
\text { stics }\end{array}$ & $\begin{array}{l}\text { Detai } \\
\text { led } \\
\text { gover } \\
\text { nment } \\
\text { budge }\end{array}$ & $\begin{array}{l}\text { Detai } \\
\text { led } \\
\text { data } \\
\text { on } \\
\text { gover }\end{array}$ & $\begin{array}{l}\text { Compa } \\
\text { ny } \\
\text { regis } \\
\text { ter }\end{array}$ & $\begin{array}{l}\text { Legis } \\
\text { latio } \\
\text { n }\end{array}$ & $\begin{array}{l}\text { Publi } \\
\text { c } \\
\text { trans } \\
\text { port } \\
\text { timet }\end{array}$ & $\begin{array}{l}\text { Inter } \\
\text { natio } \\
\text { nal } \\
\text { trade } \\
\text { data }\end{array}$ & $\begin{array}{l}\text { Healt } \\
\text { h } \\
\text { secto } \\
\text { r } \\
\text { perfo }\end{array}$ & $\begin{array}{l}\text { Prima } \\
\text { ry } \\
\text { and } \\
\text { secon } \\
\text { dary }\end{array}$ & $\begin{array}{l}\text { Crime } \\
\text { stati } \\
\text { stics }\end{array}$ & $\begin{array}{l}\text { Envir } \\
\text { onmen } \\
\text { tal } \\
\text { data }\end{array}$ & $\begin{array}{l}\text { Natio } \\
\text { nal } \\
\text { elect } \\
\text { ion } \\
\text { resul }\end{array}$ & $\begin{array}{l}\text { Publi } \\
\text { c } \\
\text { contr } \\
\text { actin } \\
\text { g }\end{array}$ \\
\hline China & 5 & 5 & 65 & 15 & 5 & 5 & 15 & 15 & 15 & 15 & 15 & 15 & 15 & 0 & 15 \\
\hline Does the data exist? & - & ○ & - & - & - & ○ & - & $\bullet$ & - & - & - & ○ & - & - & - \\
\hline $\begin{array}{l}\text { Is it available online from } \\
\text { government in any form? }\end{array}$ & ○ & - & 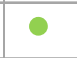 & ○ & - & $\bullet$ & 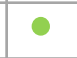 & - & - & - & - & ○ & - & - & ○ \\
\hline $\begin{array}{l}\text { Is the dataset provided in machine- } \\
\text { readable and reusable formats? }\end{array}$ & - & 0 & 0 & - & - & ? & - & ? & 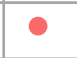 & 0 & - & 0 & - & - & - \\
\hline $\begin{array}{c}\text { Is the machine-readable and reusable } \\
\text { data available as a whole? }\end{array}$ & $\bullet$ & $\bullet$ & - & $\bullet$ & - & $\bullet$ & - & $\bullet$ & - & - & $\bullet$ & $\bullet$ & $\bullet$ & - & $\bullet$ \\
\hline $\begin{array}{c}\text { Is the dataset available free of } \\
\text { charge? }\end{array}$ & - & - & 0 & - & - & - & - & - & - & - & - & - & - & 0 & - \\
\hline Is the data open1y 1 icensed? & - & $\bullet$ & - & $\bullet$ & - & ○ & $\bullet$ & - & - & $\bullet$ & - & $\bullet$ & - & $\bullet$ & - \\
\hline Is the dataset up to date? & P & O & - & O & - & ○ & ○ & 0 & ○ & 0 & + & 0 & 0 & 0 & 0 \\
\hline $\begin{array}{c}\text { Is the dataset being kept regularly } \\
\text { updated? }\end{array}$ & ? & - & 0 & • & - & 0 & - & $\bullet$ & - & - & 0 & 0 & - & - & • \\
\hline $\begin{array}{c}\text { Was it easy to find information about } \\
\text { this dataset? }\end{array}$ & 0 & 0 & 0 & - & - & 0 & - & - & - & - & - & 0 & 0 & - & - \\
\hline $\begin{array}{c}\text { Are data identifiers provided for key } \\
\text { elements in the dataset? }\end{array}$ & 0 & • & - & • & 0 & • & - & • & - & • & • & 0 & - & ○ & ? \\
\hline
\end{tabular}

Note: green represents "Yes", red represents "No", and yellow represents "incomplete dataset update".

Figure 6. Implementation assessment results of government data openness in China in 2016. 


\subsubsection{The Current State of Impact of Government Data Openness in China}

The impact sub-indexes of ODB are relatively fixed and have not been updated. The impact is mainly assessed from three aspects: political, economic and social.

In light of assessment index, the scores of China's political, economic and social impact have not reached the average value of the Asia-Pacific region. Of which, the score of China's economic impact is the lowest. This shows that government data openness in China exerted negligible positive impact on economic development and it is difficult for the companies to take advantage of open data.

In terms of assessment questions, impact assessment of ODB covers six questions. The overall global impact level is low and many countries scored zero point in multiple assessment questions. Hence, there is not huge gap between China and other countries though China does not have high score. The ranking interval is shown in Figure 7.

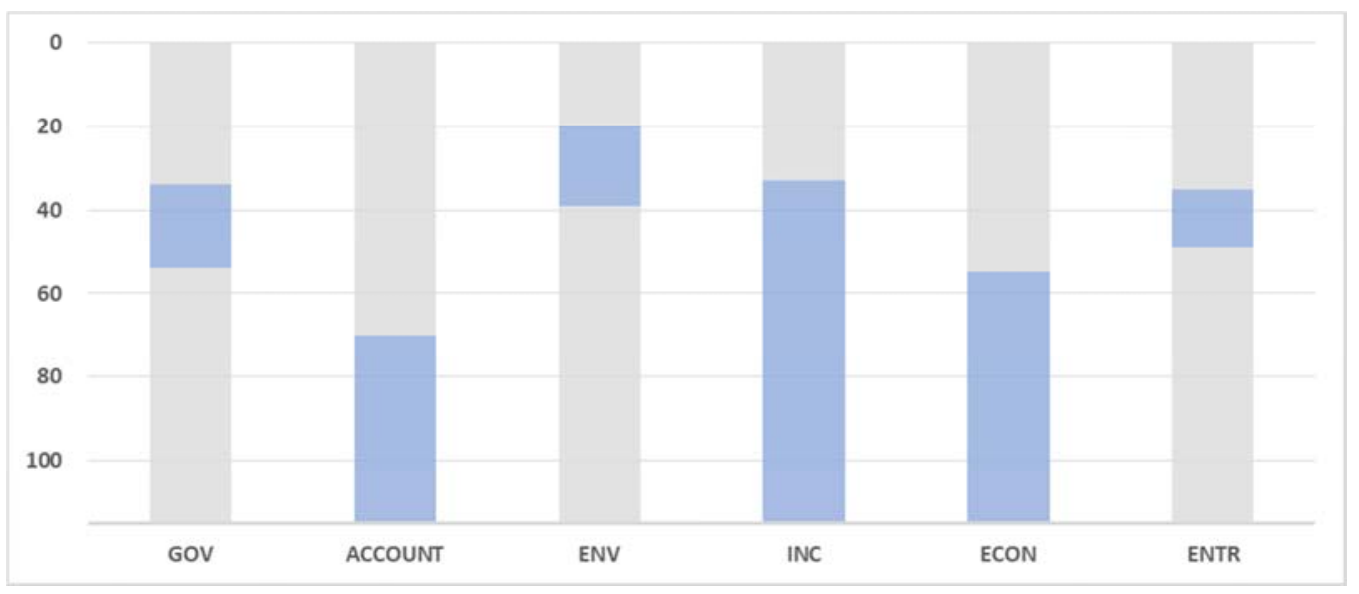

Figure 7. Ranking intervals of China in terms of score of impact assessment questions in 2016.

The total score of every impact assessment question is 10 points. In the impact assessment in 2016, China scored 2 points in the assessment question ENTR, one point in the assessment questions GOV and ENV and zero point in the assessment questions ACCOUNT, INC and ECON. Among the three assessment questions ACCOUNT, INC and ECON, more than half of the countries scored zero point in the two assessment questions INC and ECON, and 39\% of the countries scored zero point in the assessment question ACCOUNT. This shows that low impact is not unique to China but ubiquitous in the whole world.

In conclusion, based on the assessment results of ODB, China has acceptable readiness, lower implementation and negligible impact of government data openness and outstanding problems in various indexes. In combination with the index correlation of ODB, the overall level of China's government data openness can be promoted through strengthening certain index to drive other indexes. Although the promotion of impact can enhance readiness and implementation, in the practice, the readiness and implementation are indirectly promoted by their promotion measures, which is impossible to be quantitatively analyzed. Therefore, this paper mainly discusses the direct strategies towards better readiness and implementation and the expected results of promotion.

\subsection{One of the Strategies for Improving Government Data Openness in China: From the Perspective of Readiness}

\subsubsection{Measures Towards Better Readiness of Government Data Openness in China}

Readiness is the basic one among the three indexes. It is not only highly correlated with the implementation, but also more likely to decide the level of impact. Improving the readiness is an important strategy for greater government data openness in China. In view of the shortcomings in readiness of government data openness in China, in particular the backward conditions of POLI, DPL and FH, the authors summarize the following measures for better readiness of government data openness in China after referring to the advanced practices of foreign countries.

(1) Making clear of OGD strategy, policy and guidance

In 2016, China scored only one point in POLI, an assessment question under the newly increased sub-index Government Policies. The reasons lie in that China does not have any official website or government documents to guide the practice of data opening-up across the country and has not yet formed the official open data strategy and policies. According to ODB, to score above 5 points in the assessment question POLI, clear national open data policy or strategy illustrating the procedures, responsibilities, timetable and resources and implemented by specific governmental organs or institutions and formulation of general guidance documents and standards to facilitate data openness in different fields are required. The United Kingdom which scored 9 points, the highest score, in the assessment has published a series of policies advocating open data and public information as early as in 2009, such as Power of Information Taskforce Report and Putting the Frontline First: Smarter Government. In 2010, The National Archives of the United Kingdom also issued the Open Government License for Public Sector Information to guide the dataset openness of the public sectors. [19] 
(2) Developing a national level OGD action plan

The OGD action plan belongs to the assessment question INIT under the government action sub-index. China scored 3 points in such question and ranks between $62 \%$ and $66 \%$. So it is also one of the problems that must be solved immediately for China. China mainly relies on the CITY to score higher points of government action sub-index, which may partially explain why the action plan at the national level is ignored. China currently does not have national level OGD action plan and the government actions are spontaneously taken by local governments at all levels, which is prone to have the problems of non-standard and non-unified dataset openness and inconvenient use by the publics. The France which scored 9 points, the highest score, in the assessment submitted an OGD action plan every two years to the Open Government Partnership since its joining in it. The plan contains the development planning of France's government data openness.

At present, 98 countries in the world have joined the Open Government Partnership, excluding China. However, China can learn from the member countries of the Open Government Partnership, formulate a national level OGD action plan and update it regularly to ensure the steady development of China's data openness.

(3) Establishing a legal or regulatory personal data protection framework

DPL is under the citizens and civil society sub-index and examines the judicial protection over personal data in government data openness. China ranks at lower position in terms of such assessment question. The reason is that China has not yet developed legal policy specific to government data openness and hence is unable to protect the personal data. Although China has formulated Decision on Strengthening Network Information Protection, Rules for Protection of the Personal Information of Telecommunications and Internet Users and Consumer Rights Protection Law of PRC and other legal documents to protect the personal information in the Internet environment, the lack of special basic law on personal information protection [20] makes the personal data protection unable to be guaranteed in the data opening-up process. Therefore, establishing a legal or regulatory personal data protection framework as soon as possible becomes particularly important. Protecting the citizens' right to information through government data openness and protecting the citizens' privacy through personal data protection are the double requirements for government data openness in China.

\subsubsection{Expected Results After the Readiness of Government Data Openness in China Is Promoted}

After Z-score standardization over China's score in the ODB assessment carried out in 2016, the standardized score of readiness of China was 0 , that of implementation was -0.60 and that of impact was -0.37 . Only promoting some readiness sub-indexes of China by the above measures and assuming that the score of each of the three assessment questions is increased by 5 points, then China's readiness score will be increased to 0.38 after standardization, ranking 37 th place and moving up 16 places. The global ranking intervals are shown in Figure 8 and the yellow represents the interval in which China is located.

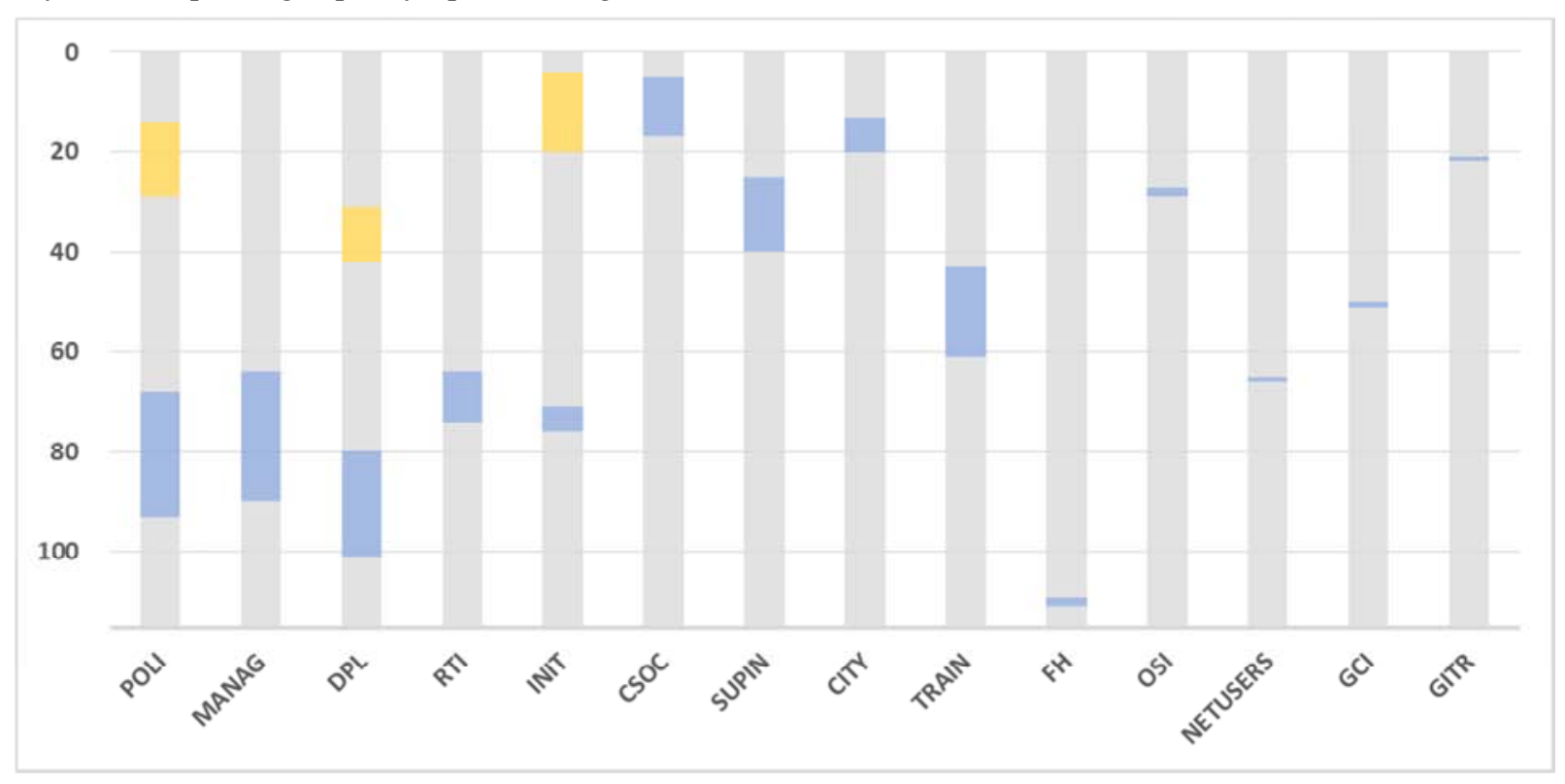

Figure 8. Expected results after China's readiness is promoted.

Then according to index correlation, the data processing on implementation and impact can be performed. As the correlation coefficient between readiness and implementation is 0.86 and the correlation coefficient between readiness and impact is 0.83 , it is expected that China's implementation can reach -0.27 and the impact can reach -0.05 after standardization, moving up 25 places and 24 places respectively. And the overall ranking will rise to 47 th place.

As shown in Figure 9, under the action of index correlation, only increasing the score of the three readiness assessment 
questions can lead to significant increase of implementation and impact and make China's ranking in ODB move up 24 places and government data openness in China reach an average level on a global scale.

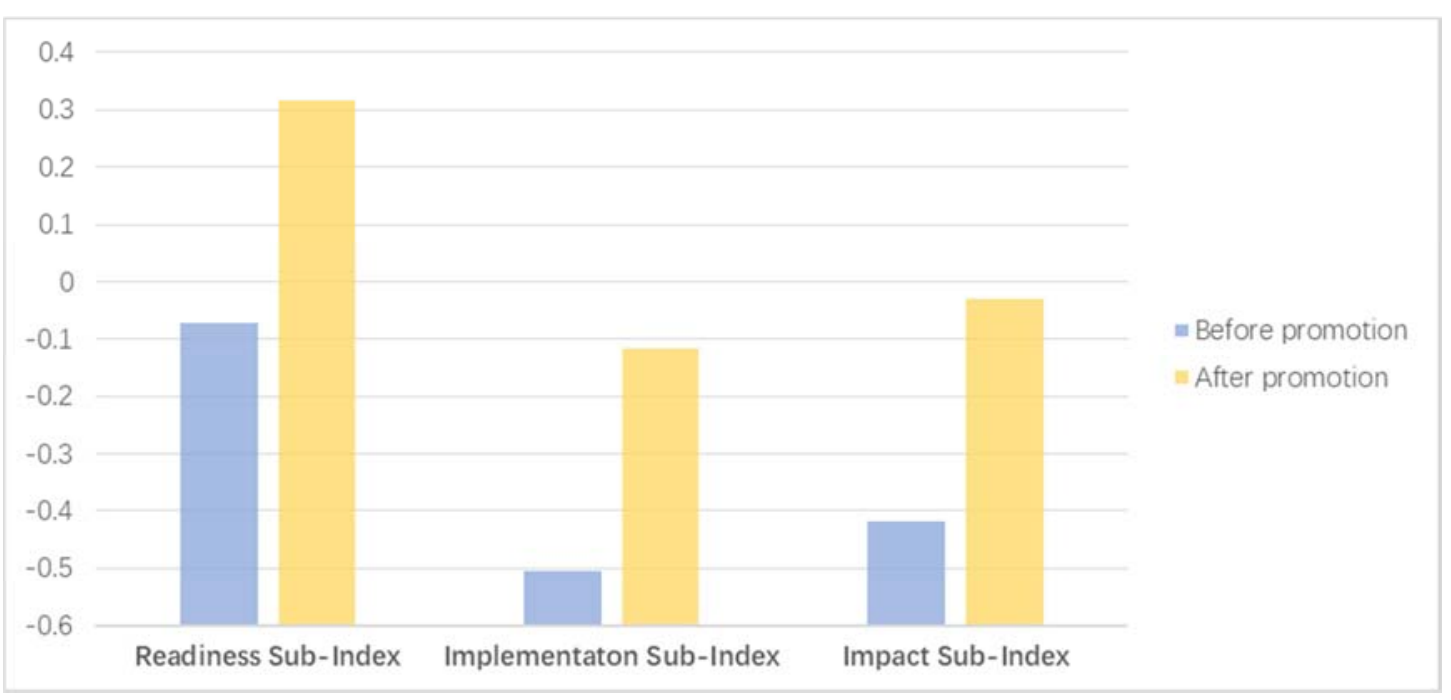

Figure 9. Overall expected results after China's readiness is promoted.

\subsection{One of the Strategies for Improving Government Data Openness in China: From the Perspective of Implementation}

\subsubsection{Measures Towards Better Implementation of Government Data Openness in China}

The implementation examines the openness level of dataset and has a certain correlation with the impact. Therefore, improving the openness of dataset can also increase the overall level of government data openness in China. In view of the shortcomings in China's implementation in ODB assessment, the promotion measures are as follows:

(1) Strengthening the licensing for data openness

If there are no explicit licenses for use of the open datasets, the users will not be able to determine whether they can use the open data. To improve the use of open datasets, the licensing for open data must be strengthened. This is also reflected in the readiness. The government should develop a clear policy to regulate the licensing for data openness so that more data which can be made public can be freed up. The government should list the public-owned permissions for access to the open datasets and a clear authorization statement is required for whether such open datasets can be obtained in batches and whether they can be tried online.

(2) Improving the proportion of machine-readable open data

Currently, China has a lower proportion of machine-readable open datasets. Only one of the 15 assessed datasets can be machine-readable. Most of the open datasets of the governmental departments are not machine-readable and all datasets do not satisfy the assessment question: is the machine-readable and reusable data available as a whole? In the ODB assessment, Brazil is the leading country in terms of implementation and ranked third place in the world in 2015. 11 of the 15 assessed datasets of Brazil are machine-readable. In comparison with Brazil, China lags far behind.
(3) Opening up the key datasets

China does not have policy strategy or action plan to guide government data opening-up. The national election dataset has not yet been opened up, the map dataset, the land ownership dataset, the set of detailed data on government spend and the company register dataset cannot be obtained online. These five datasets are those with lowest level of openness. Meanwhile, without unified guidance, the utilization rate of other datasets that have been already opened up is not high. This is because the key dataset is not freed up. In 2011, the United Kingdom released the first version of OGD action plan, but was criticized for focusing too much on the open data. The British government gradually realized that it should pay more attention to the demands of the public and open up the key dataset to facilitate use by the public. [21] In 2012, the Open Data Users Group of the United Kingdom was established. As an institution linking up the public with the government, the Open Data Users Group advises the government on the datasets that should be opened up in priority. China should also pay more attention to the demands of the users and improve the openness level of key datasets and the utilization rate of open data.

In addition, failure to provide data identifiers for key elements in the dataset is also an obvious problem in China's implementation. However, most countries in the world have also failed to meet this requirement. So this is not discussed as a strategy towards greater government data openness in this paper.

\subsubsection{Expected Results After the Implementation of Government Data Openness in China Is Promoted}

There are ten questions for dataset assessment, with total score as 100 points. According to the above implementation promotion measures, assuming that the score of each of the two assessment questions, namely, is the data openly licensed and is the dataset provided in machine-readable and reusable formats, of each dataset is increased by 5 points and under 
the prerequisite that the data will not be added of score if it has already satisfied the requirements, then China's implementation score will be increased to -0.25 after standardization, with ranking moving up 25 places. The global ranking intervals are shown in Figure 10, the yellow represents the interval in which China is located after promotion and the green represents the overlapped interval in which China is located before and after promotion.

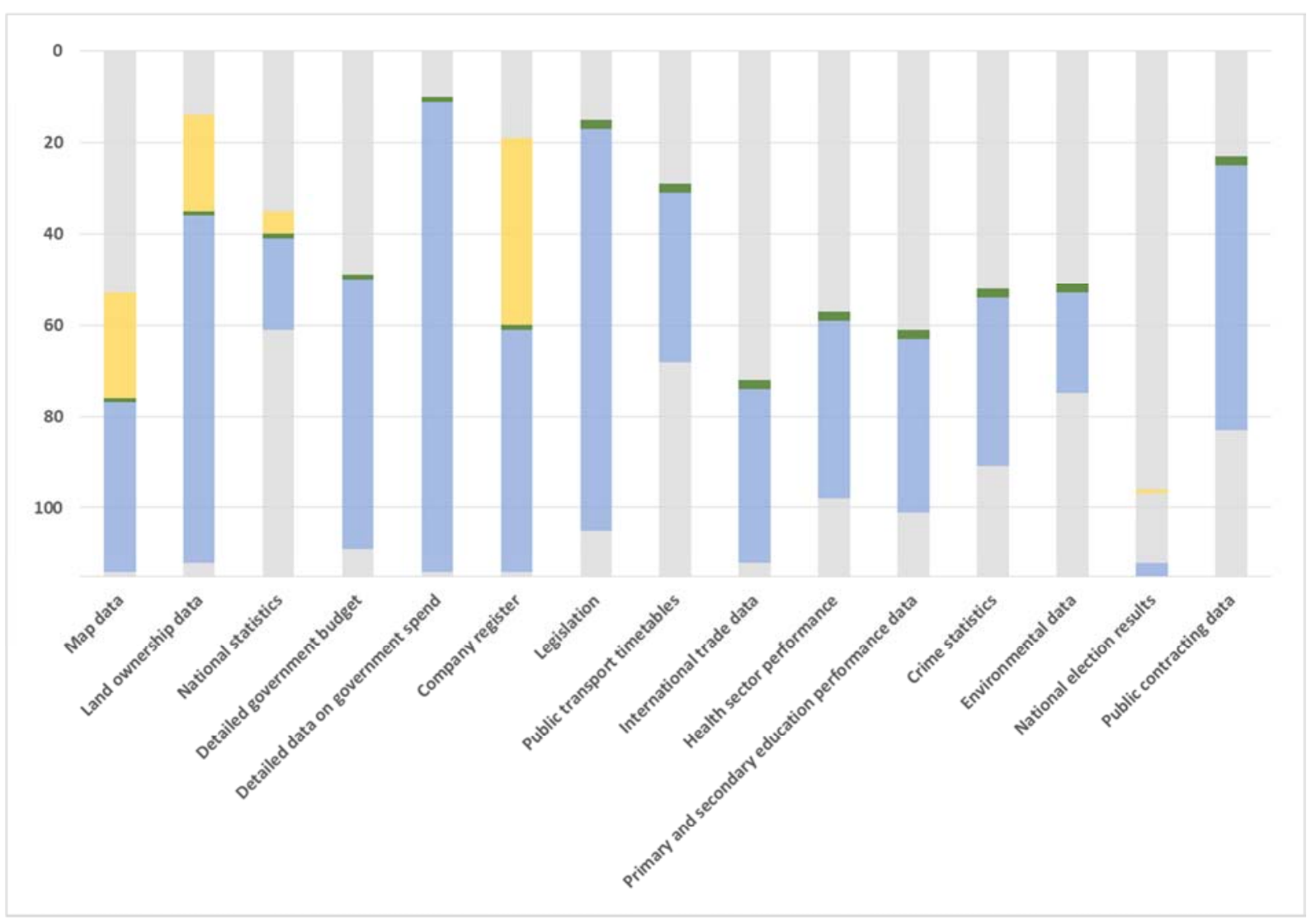

Figure 10. Expected results after China's implementation is promoted.

After increasing the score of the two assessment questions, the ranking interval of China in terms of various datasets have all moved up. The ranking interval of the 10 of the 15 datasets after promotion completely overlaps with that before promotion. Although China does not override the leading countries in terms of ranking of these datasets, the situation of significant backwardness has been basically changed. This is also a great progress.
Then based on the index correlation that the implementation can affect the impact and the fact that the correlation coefficient between implementation and impact is 0.79 , the impact will be -0.09 after promotion of the implementation, with ranking moving up 23 places. Under the circumstance that the readiness remains unchanged, the overall ranking of government data openness in China moves up to the 55 th place.

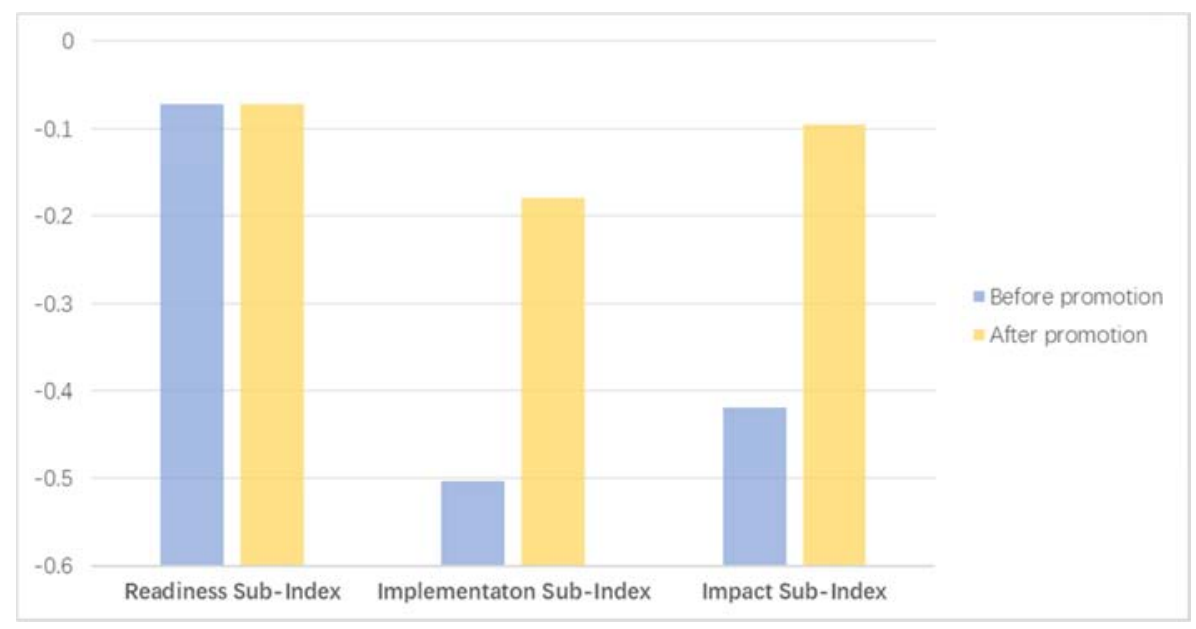

Figure 11. Overall expected results after China's implementation is promoted. 
This paper uses the index correlation to estimate the impact of an index after it is being promoted on the overall level of government data openness in China. For quantitative analysis, only the impact of the indexes of government data openness at the earlier stage on the indexes at the later stage is considered and the feedback effect of the implementation on readiness and the impact on readiness and implementation is not considered. As shown in Figure 11, when the datasets of implementation index are promoted in terms of the two assessment questions, namely is the data openly licensed and is the dataset provided in machine-readable and reusable formats, the impact will be promoted at the same time, thus making the overall level promoted.

\section{Comparative Assessments on the Measures Selection Perspective, Characteristics and Advantages of the Strategies for Improving Government Data Openness in China}

This paper summarizes two strategies for improving government data openness: from the perspectives of readiness and implementation. It can be seen from the above analysis that the rise of expected ranking by these two strategies is not much different and the expected results of the strategy from the perspective of readiness are slightly higher. According to the practice thinking of the traditional open data powers, namely United Kingdom and United States, developing readiness first can lay a solid foundation of readiness and provide favorable conditions for the subsequent data opening-up. However, focusing on readiness is not the only strategy towards greater government data openness. Brazil and other leading countries in terms of readiness do not formulate national level open data strategy and do not have sufficient readiness, either. However, they have also made significant achievements through promotion of implementation. Giving priority to implementation can greatly shorten the preparation period for data opening-up and quickly open up data to achieve the purpose of improving government transparency and facilitating the use of open data by the public. Each strategy has its own advantages. This paper provides specific methods towards greater government data openness by referring to ODB. The government can weigh and choose according to the national conditions. Any of the two strategies will promote the development of government data openness in China.

\subsection{Comparative Assessment on the Measures Selection Perspective of the Strategies for Improving Government Data Openness in China}

The measures to promote government data openness from the perspectives of readiness and implementation are based on the assessment questions which are at the lowest tier of the assessment system. However, the measures from the perspective of readiness are the assessment questions vertically constituting the sub-indexes of readiness and the measures from the perspective of implementation are the assessment questions horizontally assessing the datasets of implementation index.

The measures towards greater government data openness from the perspective of readiness are the assessment questions selected from the readiness sub-indexes that China has extremely poor performance and these assessment questions are the contents of readiness sub-indexes. However, the implementation index consists of index datasets and the index datasets are assessed by the same assessment questions. When selecting the measures, the promotion of openness of certain datasets is not considered. Instead, starting from the assessment questions to select the open data requirements that need to be improved is considered, thus achieving the goal of improving overall dataset openness.

\subsection{Comparative Assessment on the Characteristics and Advantages of the Strategies for Improving Government Data Openness in China}

\subsubsection{Comparative Assessment on the Characteristics of the Strategies for Improving Government Data Openness in CHINA}

The promotion of government data openness from the perspective of readiness is in line with the stage characteristics of government data openness and has the normative characteristics. Formulating national level OGD action plan and making clear of the relevant laws and policies will help to implement government data opening-up in China in a normative and unified way and avoid problems like low utilization rate of open data and difficulties in data resource integration in the later period.

The promotion of government data openness from the perspective of implementation can quickly respond to the needs of the public and has the time-sensitive characteristics. China has a later start in government data openness and still has inadequate readiness at present. In contrast, China can achieve a fast and effective breakthrough by focusing on implementation. Promoting the overall level of government data openness in China through promoting dataset openness from the perspective of implementation can set up China's OGD system more quickly and provide open data for use by the public.

\subsubsection{Comparative Assessment on the Advantages of the Strategies for Improving Government Data Openness in China}

Currently, China has more advantages in readiness in contrast with implementation. For China, only the readiness index has once reached the global average level in the assessment and the score was higher than that of implementation in the four assessments. From the perspective of application of index correlation, the promotion strategy from the perspective of readiness can enhance the implementation and impact simultaneously and the 
correlation between readiness and impact is stronger than that between implementation and impact. Hence, the promotion strategy from the perspective of readiness has more advantages.

However, in consideration of the practice in China, the promotion strategy from the perspective of implementation is more advantageous. Local governments of China have taken into practices and established 46 local OGD platforms. [22] The practice of data openness is being rapidly advanced by local governments at all levels. Although the practice of local government is not considered in implementation assessment of ODB, the strategy towards better implementation can also be applied in practice of local governments. In the already launched OGD platforms, strengthening the licensing for open data, improving the proportion of machine-readable open data and opening up key datasets based on the needs of the publics will provide practical experiences for establishment of unified national level OGD platform in the future.

\section{Conclusions}

The assessment results of ODB show that, in general, China has certain foundation only in terms of readiness and its implementation and impact is relatively lower. China's outstanding problems in terms of readiness are that China does not have national level government guidance and policy support, has not yet set up national level OGD platform and has not yet formed national level OGD action plan and the actions of the local governments require unified leadership. China's outstanding problems in terms of implementation are that China fails to satisfy many requirements on open data and has lower level of dataset openness and its data openness is not in line with the definition on open data and is not conducive to public use.

Based on the problems shown by the assessment results, this paper presents the exploration of the strategies for improving government data openness in China from the two perspectives of readiness and implementation. Although the ranking of the expected results by the two strategies moves up about the same and each promotion strategy has its own advantages, China needs to promote the government data openness from the perspective of readiness in the long run. In current government data openness in China, local governments take actions before the formulation and promulgation of national government policies and they actively open up the government data. However, their work is conducted without unified planning and management. If priority is given to the implementation and only promoting the dataset openness, the differences in dataset openness of local governments will become greater, thus turning advantages into disadvantages. This is detrimental to the long-term development of government data openness in China. Therefore, prioritizing the development of readiness and effectively preparing for the government data openness will be the strategy to which China needs to pay more attention. Making clear of national level government guidance and policy support, establishing national OGD platform and formulating OGD action plan will be an indispensable link in government data opening-up and also the problems asking for prompt solution in the next stage of government data openness in China.

\section{Acknowledgements}

This work is supported by the Natural Science Foundation of China (Grant 71473182), and the Major Project of the Key Bases of Humanities and Social Science of the Ministry of Education, China (Grant 13JJD870004).

\section{References}

[1] Zhou Qian. The Experiences of USA's Government Data Openness and its Enlightenment to China [J]. The Library Journal of Henan, 2015 (7):72-73.

[2] Li Yan, Zhang Shulin \& Chen Wei. The Practice, Experience and Enlightenment of UK's Government Data Openness [J] Information Science, 2016, 34 (8):148-152.

[3] Chen Tao \& Li Mingyang. Construction Strategy of Open Data Platform--With Construction of Wuhan Municipal Open Government Data Platform as Example [J]. E-government, 2015 (7):46-52.

[4] Report of China's Local Open Government Data Platform $[\mathrm{EB} / \mathrm{OL}]$. http://www.echinagov.com/news/214045.htm.

[5] Jiang Xin \& Ma Haiqun. Method and Practice of Open Government Data Assessment--Interpretation Based on Open Data Barometer Global Report [J]. Journal of Modern Information, 2016, 36 (9): 22-26.

[6] Zhang Han \& Wang Zhong. Comparison Research on Open Data of International Government [J]. Journal of Intelligence, 2015, (8):142-146, 151.

[7] Yang Dongmou, Luo Jin, Wang Huiru et al. Current Implementation of International Open Government Data [J]. E-government, 2013, (6):16-25.

[8] Cai Shijie \& Xia Yikun. Comparative Analysis of Open Government Data Strategy in Developed Countries [J]. E-government, 2015, (7):17-26.

[9] Sun Yanyan \& Lv Zhijian. Analysis of China's Open Government Data Development Strategy [J]. E-government, 2015, (5):18-24.

[10] Zhou Wenhong. The Open Data Analysis of the Canadian Federal Government and Its Enlightenment to China [J]. Documentation, Information \& Knowledge, 2015, (2):106-114.

[11] Luo Bo. Foreign Open Government Data Plan: Progress and Enlightenment [J]. Information Studies: Theory \& Application, 2014, (12):138-144.

[12] Xia Yikun. The Current Sate, Problems and Countermeasures of China's Open Government Data from the Perspective of International Comparison [J]. Library and Information Service, 2016 (7):34-40. 
[13] Huang Ruhua \& Lin Yan. The Policy and Regulation Support for Open Government Data Sharing in France and its Enlightenment to China [J]. Library, 2017 (3):1-6.

[14] Hu Yifang \& Lin Yan. The Policy and Regulation Support for Open Government Data in Canada and its Enlightenment to China [J]. E-government, 2017 (5):1-10.

[15] Tao Xidong. The Experience and Enlightenment of Open Government Data in Developed Cities of Western Countries [J]. Urban Development Studies, 2016, 23 (9):30-32.

[16] Get the data [EB/OL].[2018-07-12]. https://opendatabarometer.org/4thedition/data/.

[17] OpenDataBarometer [EB/OL].[2018-07-13].http://opendatabarometer.org/baromete $\mathrm{r} /$.

[18] Zhang Xiaojuan, Sun Cheng, Xiang Jinpeng, et al. Analysis of Index Characteristics and Model of Open Government Data based on International Assessment System [J], 2017 (2):28-40.
[19] Zhu Bei \& Sheng Xiaoping. Open Government Data Policies of the United Kingdom [J]. Library Tribune, 2016, 36 (3):121-126.

[20] Zhang Xiaojuan, Wang Wenqiang \& Tang Changle. The Policy and Regulations of China and USA on Open Government Data and Personal Privacy Protection [J]. Information Studies: Theory \& Application, 2016, 39 (1): $38-43$.

[21] Li Yan, Zhang Shulin \& Chen Wei. The Practice, Experience and Enlightenment of UK's Government Data Openness [J] Information Science, 2016, 34 (8):148-152.

[22] Report of China's Local Open Government Data Platform [EB/OL].[2018-07-12].

http://www.echinagov.com/news/214045.htm. 